\title{
Laparoscopic-assisted Gastrectomy for Gastric Cancer with D2 Lymphadenectomy: Experience with more than 500 Cases at Military Hospital, Vietnam
}

Ho Chi Thanh, Hoang Manh An, Dang Viet Dung, Nguyen Trong Hoe, Tran Doanh Hieu, Nguyen VanTiep, Lai BaThanh, Le Thanh Son*

Department of Abdominal Surgery, Military Hospital 103, Vietnam Military Medical University, Hanoi, Vietnam

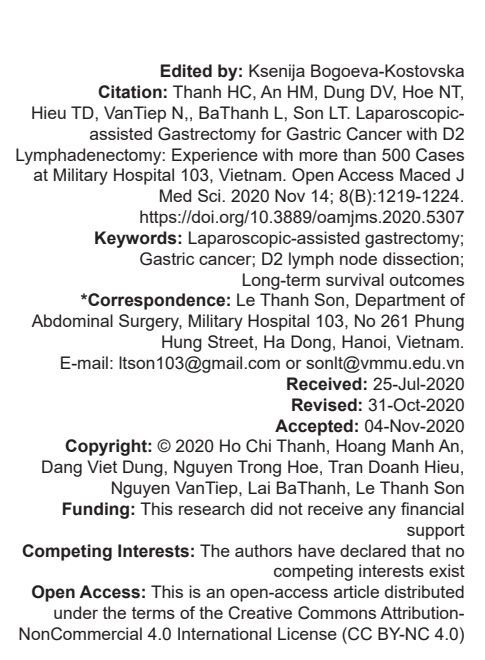

Abstract

BACKGROUND: Among the less invasive operations noted in recent years, laparoscopic gastrectomy (LG) for gastric cancer has become popular because of advances in surgical techniques. We have performed LG with D2 lymphadenectomy for 515 cases of gastric cancer between April 2009 and November 2019 at military hospital 103.

AIM: We aimed to presented the techniques and results of laparoscopic-assisted gastrectomy (LAG) for gastric cancer.

METHODS: Of the 515 gastric malignancy cases, distal gastrectomy was performed in 402 cases, proximal gastrectomy in 37 cases, and total gastrectomy in 76 cases. In all the cases, D2 lymph node dissection was performed according to the general rule of the Japanese gastric cancer association $3^{\text {rd }}$.

RESULTS: Quicker recovery was observed in the LG cases than in the open cases. The post-operative complications with this technique were within a permissible range. There was a statistical difference that was seen in the survival outcomes after LAG for gastric cancer between the laparoscopic-assisted distant, proximal, and total gastrectomy.

CONCLUSION: The laparoscopic technique is not only less invasive but also relatively safe and curative compared with open gastrectomy for advanced gastric cancer.

\section{Introduction}

Gastric cancer is the most malignant disease in gastrointestinal cancer. According to the global cancer statistics report in 2018 , the fatal was $8.2 \%$, which was the second highest and just behind lung cancer in both men and women [1]. Radical gastrectomy with lymphadenectomy is the most effective treatment, bringing life for the patient.

Laparoscopic gastrectomy (LG) was first performed by Kitano in 1991 for early gastric cancer. Up to the present many surgeons have done this technique [2], [3]. For advanced gastric cancer, gastrectomy with D2 lymph node dissection is considered the standard surgery. However, with laparoscopicassisted, surgeons suspect the radicalization of the method [4], [5]. Although among the less invasive operations noted in recent years, LG for gastric cancer with D2 lymph node dissection has become popular because of many advances in surgical techniques, the patient was less of pain, recovered quickly, and reducing days of post-operative [6], [7]. Many authors in the world have compared the results of laparoscopicassisted gastrectomy (LAG) with the same of open gastrectomy [8], [9].

We performed LG with D2 lymph node dissection for over 515 cases of gastric malignancies from April 2009 to November 2019. We would like to present our experiences and results.

\section{Subjects and Methods}

Patients selection

Patients diagnosed with gastric adenocarcinoma were performed LAG with D2 lymphadenectomy from April 2009 to November 2019 at the Department of Abdominal Surgery, Military Hospital 103. Pre-operative evaluation included gastroscopy and abdominal computed tomography (CT) scan. All of the tumors invasion was not $\mathrm{T} 4 \mathrm{~b}$ and adenocarcinomas, based on the Japanese gastric cancer treatment guidelines, ver.3 [4]. 


\section{Exclusion criteria}

(a) Patient did not agree to participate in this study; (b) patients with other malignant tumors; (c) patients with upper abdominal large operation history who cannot be fitted for LAG; (d) patients with gastric stump cancer and recurrent cancer; (e) and patients with a surgical risk greater than American society of anesthesiologists Grade III or patients with contraindications to laparoscopic surgery.

\section{Methods}

We enrolled 515 gastric cancer patients, who were LAG with D2 lymphadenectomy according to guidelines of Japanese gastric cancer association (JGCA) issued in 2011, reprinted was 2014 [10], [11] and treatment guidelines of Vietnamese Ministry of Health issued in 2013 for LG with D2 lymphadenectomy [12]. All of the patients were recorded after surgery and follow-up time. The accidents in surgery, post-operative complications, mortality, and cases of recurrence, metastases, and causes of death were recorded and confirmed.

\section{Surgical procedure}

The procedure is carried out under general anesthesia with endotracheal intubation and epidural analgesia. $\mathrm{CO}_{2}$ pneumoperitoneum is induced after insertion of the first $10 \mathrm{~mm}$ trocar at the umbilicus with a modified open technique. The patient lies on the table in the supine position, the legs apart with $45^{\circ}$, and both arms spread out. The position of the patient can be change turned right or left tilt, head high, or low, depending on the surgery [12].

The main surgeon stood on between the patient's legs, the video laparoscope assistant stood on the right of the patient, the $2^{\text {nd }}$ assistant stood on the left [13], [14] (Figure 1). Two screens were placed on both sides of the patient's head to create favorable conditions for the surgeon and the assistants to observe during the surgery.

\section{Location of trocar}

- $\quad$ We used 5 trocars (Figure 2)

- $\quad$ The first trocar was $10 \mathrm{~mm}$ just below the navel for the camera

- $\quad T h e$ second trocar was $12 \mathrm{~mm}$, on the left midclavicular line at the umbilicus

- The third trocar was $5 \mathrm{~mm}$, on the right midclavicular line at the umbilicus

- $\quad$ The fourth trocar was $5 \mathrm{~mm}$, on the right midclavicular line below the costal margin

- The fifth trocar was $5 \mathrm{~mm}$, on the left midaxillary line below the costal margin.

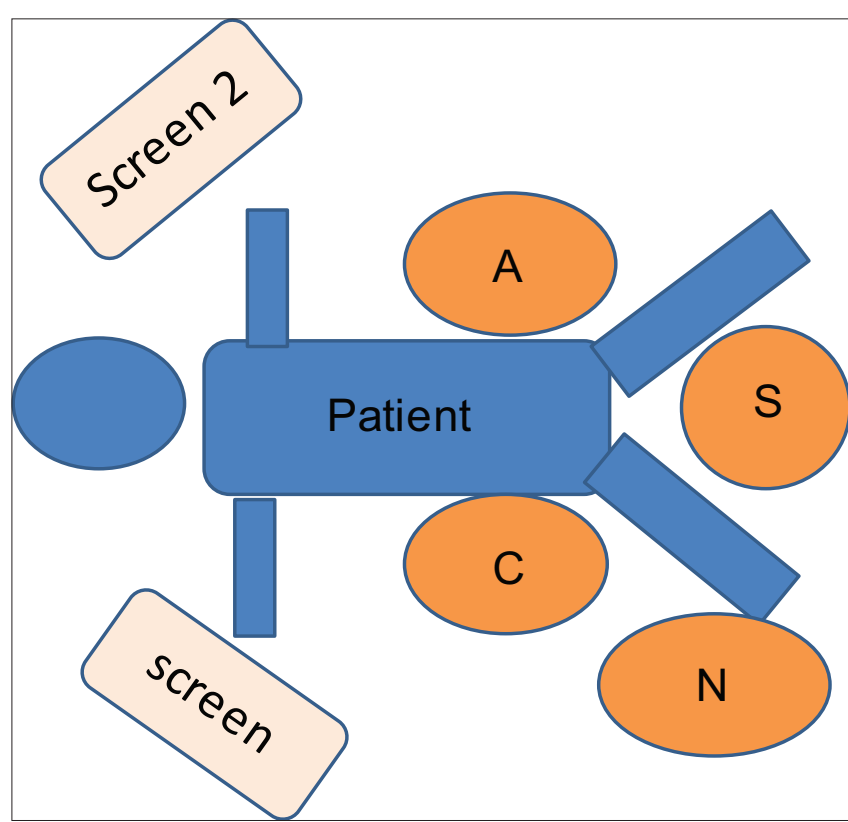

Figure 1: Positions of the patient and surgeon S: Surgeon; C: Camera; A: Assistant; N: Nurse

Handling of the resected specimen and description of histological findings

The specimens are opened along the greater curvature, cleaned, fixed, and examined the macroscopic type, location, size, and invasion of the tumor. Measurement of tumor size along the margin of mucosal lesion and the length of the proximal and distal resection margins were measured [4].

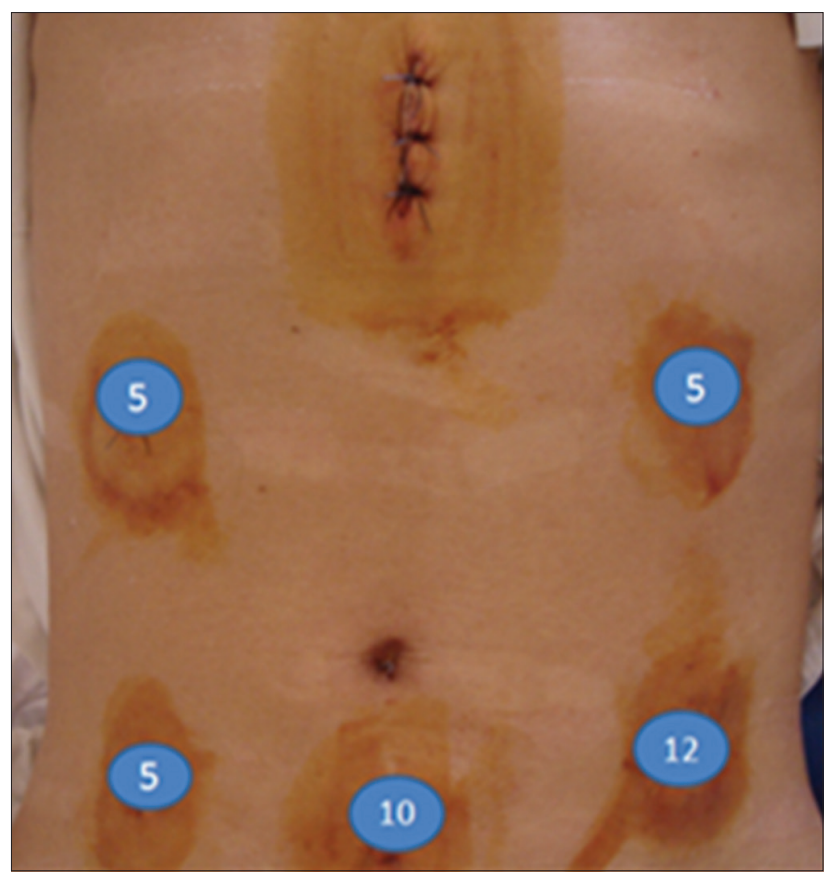

Figure 2: Trocar placement

After dissection of lymph nodes from the specimen, they were stated to a number according to the $3^{\text {rd }} \mathrm{JGCA}$, examples of the macroscopic type, number of lymph nodes, and fixed in 15-20\% formalin solution, sent to histopathology department [4]. 
The results of the postoperation stage were classified according to JGCA $3^{\text {rd }}[4]$.

\section{Follow-up and treatment after surgery}

Post-operative patients received adjuvant chemotherapy according to the Japanese gastric cancer treatment guidelines ver $4^{\text {th }}[11]$.

Every 6 months, the patients were re-examined at outpatient clinics: Examination, weight, cancer blood test marker, endoscopic, X-ray, abdominal ultrasound, abdominal CT, and positron emission tomography/CT when suspecting recurrence, metastasis.

\section{Statistical analysis}

Descriptive measures were applied for quantitative variables. We used Student's t-test for normal distribution and Mann-Whitney test for abnormal distribution. Two categorical variables were compared by the Chi-square test. All the tests in this study were 2-tailed, and the statistical significance level of 0.05 was determined. Data were stored and analyzed by IBM SPSS version 22

\section{Ethical statements}

This study was started after being approved by the ethics committee of the Vietnam military medical university.

\section{Results}

Between April 2009 and November 2019, 515 patients with gastric cancer underwent laparoscopicassisted D2 gastrectomy included 402 cases (78.05\%) of laparoscopy-assisted distal gastrectomy (LADG), $76(14.75 \%)$ of laparoscopy-assisted total gastrectomy (LATG), and 37 cases $(7.18 \%)$ of laparoscopy-assisted proximal gastrectomy (LAPG). The study included 356 male patients (69.12\%) and
159 female patients $(30.87 \%)$ with no statistically significant difference between groups. The clinical features of the study were presented in (Table 1). Body mass index in LAPG group is higher in LADG and LATG group, but there was no difference with $p=0.810$.

D2 lymphadenectomy was always performed according to the lymph node classification of the JGCA ver. 4. The operative time in LATG was $245.3 \pm 65.2$ min. The average lymph nodes were $27.8 \pm 8.34$ lymph nodes, higher than the 2 remaining groups, the difference with $p<0.001$. The size of the tumor, lymph node metastasis, and the stage of disease in the LAPG group were significantly different LADG and LATG group with $p<0.05$. According to the $3^{\text {rd }}$, JGCA classification, LATG group (53.9\%) was in stage III [10]. Most of the histopathological lesions were malignant neoplasm, and there was no difference in all three groups with $p=0.459$.

The recovery results of postoperation are shown in Table 2. The time of defecation, light exercise on the bed in three groups were not different with $p>0.05$. The duration of light feeding, removal of drainage, and post-operative days in the LATG group was significantly longer than the LADG and LAPG with $p<0.05$.

There were 7 cases of surgical accidents (1.35\%), including bleeding, colon, and spleen injury in all three groups. Post-operative complications encountered 22 cases $(4.27 \%)$, including duodenal fistula, bleeding, respiratory failure, bronchitis, gastric gangrene, anastomosis leakage, residual abscess, and wound infection. There was no difference in all three groups with $p>0.05$. Post-operative deaths (0.745) include 2 cases of respiratory failure and 1 case of gastric necrosis in the LADG group.

There were significant differences in overall survival curve between the three groups, test Log Rank $\chi^{2}=6.160 p=0.013$

Follow-up post-operative survival is shown in Table 3 and Figure 3 . The median follow-up time in the LADG group was longer. The rate of survival information was higher, and there was a difference with $p=0.013$, test Log-rank $\chi^{2}=6.160$

Table 1: Clinicopathological features laparoscopic-assisted gastrectomy with D2 lymph node dissection

\begin{tabular}{|c|c|c|c|c|}
\hline Variables & $\begin{array}{l}\text { Laparoscopy-assisted distal } \\
\text { gastrectomy }(n=402)\end{array}$ & $\begin{array}{l}\text { Laparoscopy-assisted proximal } \\
\text { gastrectomy }(n=37)\end{array}$ & $\begin{array}{l}\text { Laparoscopy-assisted total } \\
\text { gastrectomy }(n=76)\end{array}$ & $\mathrm{p}$ \\
\hline \multicolumn{5}{|l|}{ Clinicopathological features } \\
\hline Age (mean $\pm S D$, years) & $58.7 \pm 11.71$ & $56.8 \pm 8.42$ & $56.3 \pm 12.35$ & 0.163 \\
\hline Gender(male/female) $(356 / 159)$ & $279 / 123$ & $28 / 9$ & $49 / 27$ & 0.686 \\
\hline Body mass index (mean $\pm S D$ ), $\mathrm{kg} / \mathrm{m}^{2}$ & $20.2 \pm 1.87$ & $20.6 \pm 2.10$ & $20.5 \pm 1.98$ & 0.810 \\
\hline \multicolumn{5}{|l|}{ Surgical outcomes } \\
\hline Time: $($ mean $\pm S D), \min$ & $187.5 \pm 50.7$ & $165.8 \pm 45.8$ & $245.3 \pm 65.2$ & 0.000 \\
\hline Retrieved lymph node: (number) & $24.6 \pm 7.12$ & $16.7 \pm 5.66$ & $27.8 \pm 8.34$ & 0.000 \\
\hline \multicolumn{5}{|l|}{ Tumor characteristics } \\
\hline Size of tumor: $($ mean $\pm S D) \mathrm{cm}$ & $4.3 \pm 1.65$ & $3.8 \pm 1.55$ & $4.5 \pm 1.76$ & 0.002 \\
\hline Depth of invasion $\mathrm{T} 1 / \mathrm{T} 2 / \mathrm{T} 3 / \mathrm{T} 4 \mathrm{a}$ & $45 / 158 / 150 / 49$ & $6 / 15 / 12 / 4$ & 0/30/35/11 & 0.009 \\
\hline \multicolumn{5}{|l|}{ Histologic type } \\
\hline Pap/tub/muc/ring/poor & $61 / 93 / 38 / 43 / 166$ & $6 / 11 / 3 / 2 / 15$ & $9 / 13 / 11 / 15 / 28$ & 0.459 \\
\hline $\mathrm{N}$ stage: $\mathrm{pN} 0 / \mathrm{pN} 1 / \mathrm{pN} 2 / \mathrm{pN} 3$ & $140 / 85 / 91 / 86$ & $14 / 9 / 8 / 6$ & $15 / 16 / 20 / 25$ & 0.022 \\
\hline TNM stage: I/II/III & $53 / 155 / 194$ & 14/11/12 & $12 / 23 / 41$ & 0.019 \\
\hline
\end{tabular}


Table 2: Intraoperative and post-operative characteristics

\begin{tabular}{|c|c|c|c|c|}
\hline Variables & $\begin{array}{l}\text { Laparoscopy-assisted distal } \\
\text { gastrectomy }(n=402)\end{array}$ & $\begin{array}{l}\text { Laparoscopy-assisted proximal } \\
\text { gastrectomy }(n=37)\end{array}$ & $\begin{array}{l}\text { Laparoscopy-assisted total } \\
\text { gastrectomy }(n=76)\end{array}$ & $p$ \\
\hline First flatus time (h) & $50.5 \pm 8.53$ & $48.7 \pm 7.85$ & $52.4 \pm 9.97$ & 0.125 \\
\hline Times to walking (days) & $2.1 \pm 0.41$ & $1.9 \pm 0.35$ & $2.3 \pm 0.45$ & 0.078 \\
\hline Time to starting liquid diet (days) & $3.1 \pm 0.57$ & $3.5 \pm 0.85$ & $4.1 \pm 1.23$ & 0.012 \\
\hline Removal of intraabdominal drains (days) & $3.5 \pm 0.68$ & $5.0 \pm 1.26$ & $5.8 \pm 1.45$ & 0.000 \\
\hline Post-operative hospital stay (days) & $7.2 \pm 1.25$ & $7.5 \pm 1.34$ & $8.3 \pm 1.91$ & 0.017 \\
\hline Complications in surgery $7(1.35 \%)$ & $4(0.99 \%)$ & $1(2.70 \%)$ & $2(2.63 \%)$ & 0.405 \\
\hline Bleeding & 2 & 1 & 1 & \\
\hline Injure of the colon & 1 & 0 & 1 & \\
\hline Injure of the spleen & 1 & 0 & 0 & \\
\hline Post-operative complication & $17(4.22 \%)$ & $2(5.40 \%)$ & $3(3.94 \%)$ & 0.934 \\
\hline Respiratory failure & 2 & 0 & 0 & \\
\hline Bronchopneumonia & 2 & 0 & 0 & \\
\hline Intraabdominal bleeding & 1 & 0 & 1 & \\
\hline Anastomosis bleeding & 1 & 1 & 0 & \\
\hline Duodenal stump leak & 4 & 0 & 0 & \\
\hline Anastomosis leak & 1 & 0 & 1 & \\
\hline Necrotic gastric remain & 2 & 0 & 0 & \\
\hline Residual abscess & 2 & 0 & 0 & \\
\hline Wound infection & 2 & 1 & 1 & \\
\hline Mortality $3(0.58 \%)$ & $3(0.74 \%)$ & $0(0 \%)$ & $0(0 \%)$ & 0.825 \\
\hline
\end{tabular}

Table 3: Follow-up survival

\begin{tabular}{lllll}
\hline Results of follow-up & $\begin{array}{l}\text { Laparoscopy- } \\
\text { assisted distal } \\
\text { gastrectomy } \\
(\mathrm{n}=402)\end{array}$ & $\begin{array}{l}\text { Laparoscopy- } \\
\text { assisted proximal } \\
\text { gastrectomy } \\
(\mathrm{n}=37)\end{array}$ & $\begin{array}{l}\text { Laparoscopy- } \\
\text { assisted total } \\
\text { gastrectomy } \\
(\mathrm{n}=76)\end{array}$ & $\mathrm{p}$ \\
\hline Time up survival (months) & $77.1 \pm 2.803$ & $66.7 \pm 6.457$ & $60.3 \pm 6.155$ & 0.013 \\
Managing alive (n, \%) & $251(62.4)$ & $24(64.8)$ & $39(51.3)$ & 0.151 \\
Disease - free alive & 236 & 22 & 37 & \\
Disease alive & 15 & 2 & 2 & 0.156 \\
Managing death (n, \%) & $137(34.0)$ & $11(29.7)$ & $34(44.7)$ & \\
Death for recurrence & 125 & 10 & 31 & \\
Death not recurrence & 12 & 1 & 3 & 0.832 \\
Missing (n, \%) & $14(3.48)$ & $2(5.40)$ & $3(3.94)$ & \\
\hline
\end{tabular}

\section{Discussion}

This study investigated the results of LAG with D2 lymphadenectomy, including the outcome of the operation, long-term observation, operative complications, and the difficulties in surgery. We also assessed the early operative complications and initially recording far results, recurrence, and metastases.

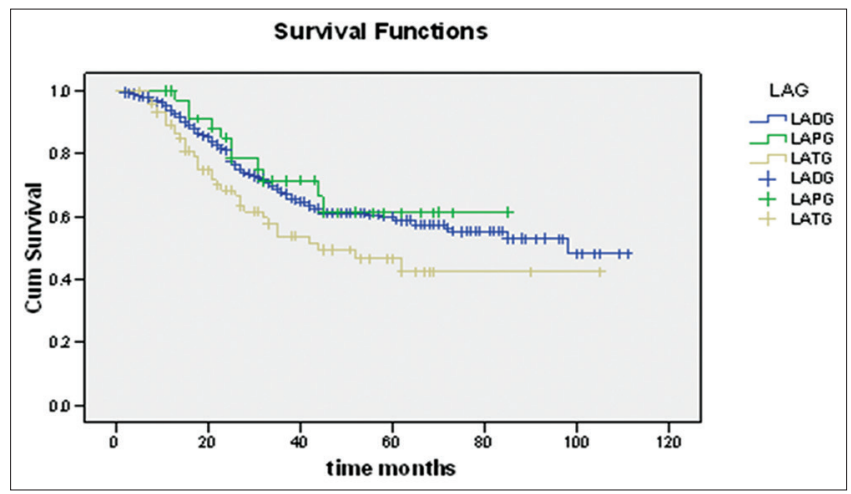

Figure 3: Kaplan-Meier survival curves according to different type of gastrectomy

Since the LADG for early gastric cancer treatment was first reported in 1994, many surgeons and major medical centers have applied this technique [15]. The number of LG has been increasing rapidly and indicated for progressive gastric cancer [16]. Many studies have demonstrated that LAG has advantages over open surgery, such as less invasive, reduced pain, quick recovery, and shorter hospital stay [5], [17], [18], [19]

The patient was placed in the supine position, and both arms were extended, two legs create angles of $45^{\circ}$. The main surgeon stood between the patient's legs, and the person holding the camera stood on the patient's right side. The first assistant was on the left side and the scrub nurse was on the right side. Our position is different from some authors who arranged the main surgeon stood on the left, the person holding the camera stood between the legs of patients [2], [13]. Through 515 operations, we found convenient for surgical step, without changing the position of the surgeon. The surgical procedure is performed through 6 main steps, similar to author Kitano's 10 steps [2] and Tanimura's 9 steps [7].

The operative time was longer in LATG than in LADG and LAPG due to the surgical process and wide lymphadenectomy. The operation for the first cases was still unfamiliar, but the latter cases gradually improved in terms of technique and shortening time equivalent to open surgery [20]. The lymphadenectomy of groups 3 and 4 is easy because it is removed with the stomach and the entire greater omentum, lesser omentum to close the right esophageal cardia to remove Group 1 , cut the right artery and left artery at the stump [21], [22] Group 6 is easy to harvest [23]. The $14 \mathrm{v}$ group is located next to the mesenteric vein on the lower right edge of the pancreas so we must hustle the pancreatic capsule before removing this group [9]. Group 5, $8^{a}$, and $12^{\mathrm{a}}$ along the common hepatic artery to the upper edge of the hepatic peduncle so our experience hustle upper pancreatic capsule, remove $8^{\mathrm{a}}$ group and lesser omentum close to the hilum of the liver [24]. Dissecting along the left of the common hepatic artery to remove lymph node 9 is located around the celiac artery, dredging and cutting the left gastric artery at the root and remove group 7 [25]. Moving to the left along the spleen artery to remove group $11 \mathrm{p}[26]$ and in case of total gastrectomy, going to the left pancreas's tail to take off group 10. Lifting the stomach, then cutting 
short gastric bundles to remove the 4sa and group 2 of the left cardia [13].

The duodenum is cut by stapler under the pylorus $2 \mathrm{~cm}$ in distal and total gastrectomy. The stapler is passed through the $12 \mathrm{~mm}$ trocar after removing the gastric sonde. Using a stapler in open surgery to cut and narrow the stomach before suturing with the jejunum [27]. Using a $25 \mathrm{~mm}$ congenital diaphragmatic hernia circle anastomosis machine to connect the stomach to the esophagus in LAPG or connect the jejunum to the esophagus in LATG, then we use the Orvil connector through the mouth to the esophagus to connect [27].

Three groups had the same catastrophic accidents $(1.35 \%)$ encountered with $p>0.05$, usually was bleeding due to spleen injure, splenic rupture, and colon injure. At the end of the surgery, we placed drainage under the liver or spleen and follow-up complications and take them off from 3 to 6 days when the patient had flatus and had a light meal. The duration for taking off drainage in LATG was longer than the LADG due to jejunumesophagus anastomosis which was narrow and easily leakage [28]. Complications in 3 groups were $4.27 \%$, including 4 cases of duodenal fistula, 2 cases of abscess, 2 cases of respiratory failure, and 2 cases of gastric necrosis. Post-operative death was 3 cases $(0.58 \%)$ both in the LADG. Two cases of deaths due to respiratory failure, both in elderly patients (male, 74, and 78-yearsold), associated with hypertension, 1 pyloric stenosis and 1 pre-operative anemia. One death due to gastric necrosis was related to nourishing anemia. Huscher et al. encountered 1 death (3.3\%) due to respiratory failure [6], and Kim et al. had 1 death (0.1\%) due to pneumonia [29].

Survival time was in Table 3 and Figure 3, the shortest follow-up time was 2 months, and the longest was 123 months, the median survival time of the three groups had different with $p=0.013$. Nineteen cases (3.68\%) had no information, 314 alive cases $(60.97 \%)$ had information, of which 295 cases without the disease $(57.28 \%)$. There were reports of deaths of 182 cases $(35.32 \%)$ of which deaths from recurrent diseases were 166 cases, and 16 cases of deaths due to other causes. The result is similar to with the author Huscher et al., the 5 -year survival rate reached $58.9 \%$, the recurrent rate was $37.9 \%$ [6]. According to Hamabe et al., the 5-year survival rate was $94.4 \%$ in the laparoscopy group and $78.5 \%$ in the open surgery group [30]. Hiki et al. followed LAG for stage I gastric cancer showed no recurrence in 5 years, the overall survival rate was $98.3 \%$, and demonstrated the long-term outcome of stage I gastric cancer after LAG equivalent to open surgery [31]. According to Park et al., the 5-year survival rate for the entire laparoscopy groups Stage I, II, and III was $87.5 \%, 77.3 \%$, and $34.8 \%$, relatively [32]. Our results were lower than that of Honda $\mathrm{M}$. due to patients with stage I gastric cancer, the overall 5-year survival rate was $97.1 \%$ [33].

In summary, a study of 515 patients advanced gastric cancer was LAG with D2 lymph nodes dissection, finding that it was technically feasible and safe. Technically can be done by the surgical team with high skill of laparoscopic surgery. The patients had less pain, faster recovery, and shorter post-operative hospital stays.

Follow-up survival of after surgery, there were 314 patients alive $(60.97 \%)$, of which 295 cases were disease-free survival. There were 182 cases of death $(35.33 \%)$, of which 166 cases of death were for recurrence and metastatic. There was a difference of survival time between LADG, laparoscopic-assisted pancreaticoduodenectomy, and LATG in this study.

\section{References}

1. Bray F, Ferlay J, Soerjomataram I, Siegel RL, Torre LA, Jemal A. Global cancer statistics 2018: GLOBOCAN estimates of incidence and mortality worldwide for 36 cancers in 185 countries. CA Cancer J Clin. 2018;68(6):394-424. https://doi. org/10.3322/caac.21492

PMid:30207593

2. Kitano S, Etoh T, Shiraishi N. Laparoscopic gastrectomy. In: Kaminishi M, Takubo K, Mafune K, editors. The Diversity of Gastric Carcinoma. Tokyo: Springer; 2005. p. 287-98. https:// doi.org/10.1007/4-431-27713-7_21

3. Yang HK. Trends of laparoscopic gastrectomy in Korea In: Kitano S, Yang HK, editors. Laparoscopic Gastrectomy for Cancer. Tokyo: Springer; 2012. p. 7-9. https://doi. org/10.1007/978-4-431-54003-8_2

4. Japanese Gastric Cancer Association. Japanese gastric cancer treatment guidelines 2010 (ver. 3). Gastric Cancer. 2010;14(2):113-23. https://doi.org/10.1007/s10120-011-0042-4 PMid:21573742

5. Katai H, Lim JS. Indications of laparoscopic gastrectomy for gastric cancer. In: Kitano S, Yang HK, editors. Laparoscopic Gastrectomy for Cancer. Tokyo: Springer; 2012. p. 19-22. https://doi.org/10.1007/978-4-431-54003-8_5

6. Huscher CG, Mingoli A, Sgarzini G, Sansonetti A, Di Paola M, Recher A, et al. Laparoscopic versus open subtotal gastrectomy for distal gastric cancer, five-year results of a randomized prospective trial. Ann Surg. 2005;241(2):232-7. https://doi. org/10.1097/01.sla.0000151892.35922.f2 PMid:15650632

7. Tanimura S, Higashino M, Fukunaga $Y$, Takemura M, Tanaka $Y$, Fujiwara $\mathrm{Y}$, et al. Laparoscopic gastrectomy for gastric cancer: Experience with more than 600 cases. Surg Endosc. 2008;22(5):1161-4. https://doi.org/10.1007/s00464-008-9786-2 PMid:18322744

8. Song KY, Kim SN, Park CH. Laparoscopy-assisted distal gastrectomy with D2 lymph node dissection for gastric cancer: Technical and oncologic aspects. Surg Endosc. 2008;22(3):6559. https://doi.org/10.1007/978-4-431-54003-8_12

PMid:17593447

9. Chen QY, Huang CM, Lin JX, Zheng CH, Li P, Xie JW, et al Laparoscopy-assisted versus open D2 radical gastrectomy for advanced gastric cancer without serosal invasion: A case control study. World J Surg Oncol. 2012;10:248. https://doi. org/10.1186/1477-7819-10-248

PMid:23158876

10. Japanese Gastric Cancer Association. Japanese classification 
of gastric carcinoma: $3^{\text {rd }}$ English edition. Gastric Cancer. 2011;14(2):101-12. https://doi.org/10.1007/s10120-011-0041-5 PMid:21573743

11. Japanese Gastric Cancer Association. Japanese gastric cancer treatment guidelines 2014 (ver. 4). Gastric Cancer. 2017;20(1):119. https://dx.doi.org/10.1007\%2Fs10120-016-0622-4 PMid:27342689

12. Vietnamese Ministry of Health. Laparoscopic Distant Gastrectomy with D2 Lymphadenectomy For Gastric Cancer, List of Guiding Medical Examination and Treatment Procedures Specialized in Oncology. Promulgated Together with Decision No 3338/QĐ-BYT. Vietnam: Ministry of Health; 2013. p. 273-6.

13. Wang DG, He L, Zhang Y, Yu JH, Chen Y, Xia MJ, et al. Anatomy of laparoscopy-assisted distal $\mathrm{D} 2$ radical gastrectomy for gastric cancer. Transl Gastrointest Cancer. 2013;2(1):73-9.

14. Kim YW, Ryu SY, Nagai Y. Position of the patient and operators, and placement of ports. In: Kitano S, Yang HK, editors. Laparoscopic Gastrectomy for Cancer. Tokyo: Springer; 2012. p. 45-7. https://doi.org/10.1007/978-4-431-54003-8_10

15. Kitano S, Shiraishi N, Uyama I, Sugihara K, Tanigawa N. A multicenter study on oncologic outcome of laparoscopic gastrectomy for early cancer in Japan. Ann Surg. 2007;245(1):68 72. https://dx.doi.org/10.1097\%2F01.sla.0000225364.03133.f8 PMid:17197967

16. Du X, Li R, Chen L, Shen D, Li S, Guo Q. Laparoscopy-assisted D2 radical distal gastrectomy for advanced gastric cancer: Initial experience. Chin Med J (Engl). 2009;122(12):1404-7. PMid:19567161

17. Cai J, Wei D, Gao CF, Zhang CS, Zhang H, Zhao T. A prospective randomized study comparing open versus laparoscopy assisted D2 radical gastrectomy in advanced gastric cancer. Dig Surg. 2011;28(5-6):331-7. https://doi.org/10.1159/000330782 PMid:21934308

18. Cui M, Xing JD, Yang W, Ma YY, Yao ZD, Zhang N, et al. D2 dissection in laparoscopic and open gastrectomy for gastric cancer. World J Gastroenterol. 2012;18(8):833-9. https://doi. org/10.3748/wjg.v18.i8.833

PMid:22371644

19. Chun HT, Kim KH, Kim MC, Jung GJ. Comparative study of laparoscopy assisted versus opensubtotal gastrectomy for pT2 gastric Cancer. Yonsei Med J. 2012;53(5):952-9. https://doi. org/10.3349/ymj.2012.53.5.952

PMid:22869478

20. Kim HS, Kim MG, Kim BS, Yook JH, Kim BS. Totally laparoscopic total gastrectomy using endoscopic linear stapler: Early experiences at one institute. J Laparoendosc Adv Surg Tech A. 2012;22(9):889-97. https://doi.org/10.1089/lap.2012.0238 PMid:23137114

21. Sakuramoto S, Yamashita K, Kim W. Dissection of lymph nodes along the lesser curvature (nos. 1, 3 lymph nodes). In: Kitano S, Yang HK, editors. Laparoscopic Gastrectomy for Cancer. Tokyo: Springer; 2012. p. 85-8. https://doi. org/10.1007/978-4-431-54003-8_19

22. Lee JH, Kim CY, Kodera Y, Fujiwara M. Dissection of the greater omentum and left gastroepiploic vessels (4ab and $4 \mathrm{~d}$ lymph nodes). In: Kitano S, Yang HK, editors. Laparoscopic Gastrectomy for Cancer. Tokyo: Springer; 2012. p. 65-7. https:// doi.org/10.1007/978-4-431-54003-8_14

23. Fukunaga $\mathrm{T}$, Lee $\mathrm{JH}, \mathrm{Kim} \mathrm{CY}$. Dissection of the right gastroepiploic vessels: Infrapyloric lymph nodes (station 6). In: Kitano S, Yang HK, editors. Laparoscopic Gastrectomy for Cancer. Tokyo: Springer; 2012. p. 69-73. https://doi. org/10.1007/978-4-431-54003-8_15

24. Sohn TS, Lee JH, Takiguchi S, Doki Y. Dissection of the right gastric vessels (no. 5 lymph nodes). In: Kitano S, Yang HK, editors. Laparoscopic Gastrectomy for Cancer. Tokyo: Springer; 2012. p. 75-7. https://doi.org/10.1007/978-4-431-54003-8_16

25. Kojima K, Sugihara K, Sohn TS, Lee JH. Dissection of lymph nodes around the common hepatic artery and celiac artery (nos. 7, 8a, 9 lymph nodes). In: Kitano S, Yang HK, editors. Laparoscopic Gastrectomy for Cancer. Tokyo: Springer; 2012. p. 79-80. https://doi.org/10.1007/978-4-431-54003-8_17

26. Kim W, Katai H. Dissection of lymph nodes around the splenic artery (no. 11p lymph nodes). In: Kitano S, Yang HK, editors. Laparoscopic Gastrectomy for Cancer. Tokyo: Springer; 2012. p. 81-3. https://doi.org/10.1007/978-4-431-54003-8_18

27. Song KY, Lee YJ, Shiraishi N. Use of linear and circular staplers. In: Kitano S, Yang HK, editors. Laparoscopic Gastrectomy for Cancer. Tokyo: Springer; 2012. p. 53-6. https://doi. org/10.1007/978-4-431-54003-8_12

28. Lee SW, Nomura E, Bouras G, Tokuhara T, Tsunemi S, Tanigawa N. Long-term oncologic outcomes from laparoscopic gastrectomy for gastric cancer: A single-center experience of 601 consecutive resections. J Am Coll Surg. 2010;211(1):33-40. https://doi.org/10.1016/j.jamcollsurg.2010.03.018 PMid:20610246

29. Kim KH, Kim MC, Jung GJ, Kim HH. Long-term outcomes and feasibility with laparoscopy-assisted gastrectomy for gastric cancer. J Gastric Cancer. 2012;12(1):18-25. https://doi. org/10.5230/jgc.2012.12.1.18

PMid:22500260

30. Hamabe A, Omori T, Tanaka K, Nishida T. Comparison of longterm results between laparoscopy assisted gastrectomy and open gastrectomy with D2 lymph node dissection for advanced gastric cancer. Surg Endosc 2012;26(6):1702-9. https://doi. org/10.1016/j.amjsurg.2013.09.028

PMid:22207307

31. Hiki N, Katai H, Mizusawa J, Nakamura K, Nakamori M, Yoshikawa T, et al. Long-term outcomes of laparoscopy-assisted distal gastrectomy with suprapancreatic nodal dissection for clinical stage I gastric cancer: A multicenter phase II trial (JCOG0703). Gastric Cancer. 2018;21(1):155-61. https://doi. org/10.1007/s10120-016-0687-0 PMid:28093654

32. Park JH, Jeong SH, Lee YJ, Kim TH. Comparison of long term oncologic outcomes of laparoscopic gastrectomy and open gastrectomy for advanced gastric cancer: A retrospective cohort study. Korean J Clin Oncol. 2018;14:21-9. https://doi. org/10.14216/kjco.18004

33. Honda M, Hiki N, Kinoshita T, Yabusaki H, Abe T, Nunobe S, et al. Long-term outcomes of laparoscopic versus open surgery for clinical stage I gastric cancer: The LOC-1 study. Ann Surg. 2016;264(2):214-22. https://doi.org/10.1097/ sla.0000000000001654

PMid:27115899 